\title{
Commentary Patients with cancer on the ICU: the times they are changing
} Evert de Jonge ${ }^{1}$ and Monique $\mathrm{M} \mathrm{Bos}^{2}$

\author{
1Department of Intensive Care, Academic Medical Center, 1100 DD Amsterdam, the Netherlands \\ ${ }^{2}$ Department of Internal Medicine and Oncology, Reinier de Graaf Hospital, Reinier de Graafweg 3, 2625 AD Delft, the Netherlands
}

Corresponding author: Evert de Jonge, e.dejonge@amc.uva.nl

Published: 2 March 2009

This article is online at http://ccforum.com/content/13/2/122

(C) 2009 BioMed Central Ltd

Critical Care 2009, 13:122 (doi:10.1186/cc7721)

See related research by Taccone et al., http://ccforum.com/content/13/1/R15

\begin{abstract}
A recent paper by Taccone and coworkers showed that $15 \%$ of patients from 198 European intensive care units (ICUs) had a malignancy, mostly solid tumors but also hematological malignancies. Over the past years, the prognosis of cancer patients has improved significantly, even when ICU admission is necessary. Refusal of ICU admission should not be based on a diagnosis of cancer as the underlying condition. In contrast, these decisions should be based on the availability of treatment options, and on patients' own preferences.
\end{abstract}

Advances in oncological and supportive care have led to improved prognoses and extension of survival time in cancer patients. Such progress, however, has involved aggressive therapy and support. Consequently, increasing numbers of patients with cancer require admission to intensive care units (ICUs).

In the last issue of Critical Care, Dr Taccone and coworkers [1] reported that patients with cancer represent a large proportion of ICU patients. In their substudy from the Sepsis Occurrence in Acutely III Patients (SOAP) study conducted in 198 European ICUs, 15\% of patients had a malignancy, mostly solid tumors but also hematological malignancies. These findings are in accordance with results from the SAPS-3 study, performed in 2002 in an international population comprising almost 20,000 ICU patients; these results showed that $3 \%$ of these patients had metastatic cancer, $6 \%$ had non-metastatic cancer and $2 \%$ had hematological cancer [2].

The high number of cancer patients treated on ICUs is remarkable. Less than 10 years ago, in guidelines for ICU admission, a taskforce of the American College of Critical Care Medicine concluded that patients with hematological or metastasized solid malignancies were poor candidates for ICU admission [3]. These patients were considered to have a very high risk (up to 90\%) of mortality. At that time, immediate treatment limitations or even refusal of ICU admission for these patients were advocated [4].

In contrast with the very poor prognosis reported in the literature, Taccone and coauthors reported much lower hospital mortality of $58 \%$ in ICU patients with hematological cancer and $27 \%$ in patients with solid malignancies, compared with $23 \%$ in ICU patients without cancer. Others have also reported the improvement in prognosis after ICU admission for patients with hematological cancer. In hematopoietic stem cell transplant recipients who received invasive mechanical ventilation, mortality was uniformly higher than $90 \%$ in studies before 1993 , but gradually decreased to $52 \%$ in 2000 [5]. In addition to advances in stem cell transplantations, improvements in critical care may have contributed to this improvement in prognosis for these patients. Clearly, patients should no longer be refused admission to ICUs only because they have hematological cancer. A relapsed/ refractory state of leukemia and a poor Sequential Organ Failure Assessment (SOFA) score were found to be the independent risk factors associated with mortality in patients with acute leukemia [6] and should be considered when decisions regarding ICU admission are made about patients with hematological cancer. In the study by Dr Taccone and colleagues, no information was available about the state of the cancers. The relation between SOFA score and mortality was confirmed in their population.

It should be noted that patients with solid cancers form a very heterogeneous population, with many different forms of cancer, different oncological treatments and different reasons for admission to the ICU. Most ICU patients with cancer are admitted after surgery, often as primary treatment for their cancers, and the short-term prognosis of these patients is mostly good. In patients after transhiatal esophageal 
resection for esophageal cancer, hospital mortality may be as low as 3.5\% [7]. Likewise, mortality after pancreaticoduodenectomy in patients with pancreatic cancer may be less than $5 \%$ in experienced centers [8]. The outcome after major oncological surgery may be mostly related to the surgical procedure, more than to the critical care on the ICU. Only limited data are available about patients with cancer admitted to ICUs for other reasons than post-operative care after oncological surgery. Azoulay and coauthors [9] reported 30 -day mortality of $58 \%$ in patients admitted for medical reasons. In a Brazilian study involving 1,090 patients with cancer requiring ICU admission for reasons other than routine postoperative care, hospital mortality was 51\% and 6-month mortality was $61 \%$. Most of these patients had nonmetastasized solid cancer, and most patients required mechanical ventilation. In patients with a prolonged ICU length of stay, mortality was independently associated with the number of failing organs, age and performance scale score [10].

Clearly, ICU treatment is not futile for all patients with cancer. Despite these recent data, rates of refusal of ICU admission in cancer patients remain high [11] and the criteria on which triage decisions are based differ between oncologists and intensivists. Decisions to withhold life-sustaining treatments are more often made for patients with cancer than patients with other terminal diseases, even when these other diseases have at least the same poor prognosis. This has been demonstrated clearly for patients dying from chronic heart failure compared to patients with metastatic cancer [12].

Over the past years the prognosis of cancer patients has improved significantly, even when ICU admission is necessary. Refusal of ICU admission should not be based on the diagnosis of cancer as the underlying condition. In contrast, these decisions should be based on the availability of treatment options, and on patients' own preferences. Unfortunately, current prognostic models for ICU patients, all based on data from the first 24 hours after ICU admission, such as APACHE (Acute Physiology and Chronic Health Evaluation) II and SAPS (Simplified Acute Physiology Score) II, can not reliably predict whether cancer patients will survive ICU admission $[4,13]$. When in doubt, it may be a very good option to start full unlimited treatment for a few days. Discontinuation of treatment should be considered if progressive organ failure is seen after 3 to 5 days [4].

\section{Competing interests}

The authors declare that they have no competing interests.

\section{References}

1. Taccone FS, Artigas AA, Sprung CL, Moreno R, Sakr Y, Vincent $\mathrm{JL}$ : Characteristics and outcomes of cancer patients in European ICUs. Crit Care 2009, 13:R15.

2. Metnitz PG, Moreno RP, Almeida E, Jordan B, Bauer P, Campos RA, lapichino G, Edbrooke D, Capuzzo M, Le Gall JR; SAPS 3 investigators: SAPS 3 - from evaluation of the patient to evaluation of the intensive care unit. Part 1: Objectives, methods and cohort description. Intensive Care Med 2005, 31:13361344.

3. Task Force of the American College of Critical Care Medicine, Society of Critical Care Medicine: Guidelines for intensive care unit admission, discharge, and triage. Crit Care Med 1999, 27: 633-638.

4. Azoulay E, Bele N, Thiery G, Schlemmer B: An alternative to refusing ICU admission of cancer patients. In 25 years of progress and innovation in Intensive Care Medicine. Edited by Kuhlen R, Moreno R, Ranieri M, Rhodes A. Berlin: Medizinisch Wissenschaftliche Verlegsgesellschaft; 2007: 449-461.

5. Afessa B, Tefferi A, Dunn WF, Litzow MR, Peters SG: Intensive care unit support and acute physiology and chronic health evaluation III performance in hematopoietic stem cell transplant recipients. Crit Care Med 2003, 31:1715-1721.

6. Park HY, Suh GY, Jeon K, Koh W-J, Chung MP, Kim H, Kwon OJ, Kim K, Jang JH, Jung CW, Kang E, Kim M-J: Outcome and prognostic factors of patients with acute leukemia admitted to the intensive care unit for septic shock. Leukemia Lymphoma 2008, 49:1929-1934.

7. van Sandick JW, van Lanschot JJ, ten Kate FJ, Tijssen JG, Obertop $\mathrm{H}$ : Indicators of prognosis after transhiatal esophageal resection without thoracotomy for cancer. J Am Coll Surg 2002, 194:28-36.

8. Van Geen RC, Gouma DJ: Impact of hospital volume on inhospital mortality in pancreatic surgery. Surg Technol Int 2002, 10:61-65.

9. Azoulay E, Moreau D, Alberti C, Leleu G, Adrie C, Barboteu M, Cottu P, Levy V, Le Gall JR, Schlemmer B: Predictors of shortterm mortality in critically ill patients with solid malignancies. Intensive Care Med 2000, 26:1817-1823.

10. Soares M, Salluh JI, Torres VB, Leal JV, Spector N: Short- and long-term outcomes of critically ill patients with cancer and prolonged ICU length of stay. Chest 2008, 134:520-526.

11. Garrouste-Orgeas M, Montuclard L, Timsit JF, Reignier J, Desmettre T, Karoubi $P$, Moreau D, Montesino L, Duguet A, Boussat $S$, Ede C, Monseau Y, Paule T, Misset B, Carlet J; French ADMISSIONREA Study Group: Predictors of intensive care unit refusal in French intensive care units: a multiple-center study. Crit Care Med 2005, 33:750-755.

12. Tanvetyanon $\mathrm{T}$, Leighton JC: Life-sustaining treatments in patients who died of chronic congestive heart failure compared with metastatic cancer. Crit Care Med 2003, 31:60-64.

13. den Boer S, de Keizer NF, de Jonge E: Performance of prognostic models in critically ill cancer patients - a review. Crit Care 2005, 9:R458-463. 